\title{
Environmentally friendly pathways for the evaluation of investment projects using life cycle assessment (LCA) and life cycle cost analysis (LCCA)
}

\author{
Joanna Kulczycka ${ }^{1} \cdot$ Marzena Smol $^{2}$
}

Received: 17 July 2015/Accepted: 16 October 2015/Published online: 24 October 2015

(c) The Author(s) 2015. This article is published with open access at Springerlink.com

\begin{abstract}
Issues related to improvement in the quality of products and to environmental protection in the economic policy of many countries and in the strategies of institutions and international organisations (e.g. European Union) have increased in importance in recent years as a consequence of the increase in environmental awareness of consumers. All these institutions currently recommend a comprehensive assessment of the effectiveness of planned projects during the decision-making process taking into account both economic and environmental factors. It is, therefore, important to develop methods and tools to assess environmental performance as a support to a proper choice of investment activities. The aim of this paper is to develop algorithms to link the life cycle assessment (LCA) model associated with environmental issues and the life cycle cost analysis (LCCA) model associated with economic factors to permit an integrated assessment of investment projects. The combination of LCA and LCCA results enables the assessment of ongoing or planned investments and should be used as a priority in making strategic decisions. In this paper, three environmentally friendly pathways (algorithms) using LCA-LCCA indicators as a support for decision-making processes were proposed: the first for implementing any environmental investments, the second for modernisation and innovation investments, and the third for new investments.
\end{abstract}

Marzena Smol

smol@meeri.pl; smol@min-pan.krakow.pl

1 AGH University of Science and Technology, Gramatyka 10, 30-067 Cracow, Poland

2 The Mineral and Energy Economy Research Institute of the Polish Academy of Sciences, Wybickiego 7, 31-261 Cracow, Poland
Keywords Decision-making process - Life cycle assessment (LCA) - Life cycle cost analysis (LCCA) · Investment project $\cdot$ Environmentally friendly management

$\begin{array}{ll}\text { Abbreviations } \\ \text { BAT } & \text { Best available techniques } \\ \text { BATNEEC } & \text { Best available technology not entailing } \\ & \text { excessive cost } \\ \text { BREF } & \text { BAT reference document } \\ \text { CML-IA } & \text { Life cycle impact assessment methodology } \\ \text { CO } 2 \text { eq } & \text { CO }_{2} \text { equivalent } \\ \text { EIA } & \text { Environmental impact assessment } \\ \text { EMAS } & \text { Eco-management and audit scheme } \\ \text { EMS } & \text { Environmental management system } \\ \text { EU } & \text { European Union } \\ \text { EC } & \text { European Commission } \\ \text { Impact } & \text { Life cycle impact assessment methodology } \\ \text { 2002+ } & \\ \text { IRR } & \text { Internal rate of return } \\ \text { ISO } & \text { International Organization For } \\ \text { JRC } & \text { Standardization } \\ \text { LCA } & \text { Joint Research Centre } \\ \text { LCC } & \text { Life cycle assessment } \\ \text { LCCA } & \text { Life cycle costs } \\ \text { LCIA } & \text { Life cycle cost analysis } \\ \text { LCIRR } & \text { Life cycle impact assessment } \\ \text { LCMIRR } & \text { Life cycle-internal rate of return } \\ \text { LCNPV } & \text { Life cycle-modified internal rate of return } \\ \text { LCPI } & \text { Life cycle-net present value } \\ \text { MIRR } & \text { Life cycle-profitability index } \\ \text { NPV } & \text { Nodified internal rate of return } \\ \text { OEF } & \text { Organisation environmental footprint } \\ \text { PEF } & \text { Product environmental footprint } \\ \text { PI } & \text { Profility index } \\ & \end{array}$




$\begin{array}{ll}\text { PDCA } & \text { Plan-do-check-act } \\ \mathrm{Pt} & \text { Endpoints } \\ \mathrm{SF} & \text { Structural funds }\end{array}$

\section{Introduction}

The appropriate selection of investment projects is nowadays one of the most significant challenges in company management all over the world (Monteiro et al. 2009). The implementation of an investment project must be carried out in accordance with the principles of sustainable development (Monteiro et al. 2009) and, therefore, economic, social, and environmental (Michelsen and Fet 2010) aspects must be considered and integrated (Kravanja et al. 2012).

In recent years, dynamic growth of expenditure on environmental protection has been observed in European Union (EU) countries (Tsireme et al. 2012). Access to EU funds has allowed significant resources for the financing of investment and ecological activities to accumulate in some countries. Initially, the criteria for the granting of financial assistance were very lax, but over time more and more attention has been paid to the selection of investment projects which fulfil both economic and ecological criteria (Lewandowska et al. 2013). Given the importance of public procurement, it is certain that an increased focus on environmental performance in the public sector will have a great impact on business (De Benedetto and Klemeš 2010). Those companies that are not able to provide information about their environmental performance and the life cycle costs (LCC) of products (Akhtar et al. 2014) could have difficulties in getting contracts with the public sector both now and in the future. A consequence of this is that measures of environmental performance are becoming steadily more common in all branches of industry (Elms and ElHalwagi 2010). Therefore, it is important to develop methods and tools to assess environmental performance (Jasch 2003), in particular for investment related to environmental protection (Zhu et al. 2014). The European Commission has taken on this challenge in, among other publications, the Communication 'Roadmap to a Resource Efficient Europe' (COM 571 2011). The European Commission (EC) pledged to establish a common methodological approach to enable Member States and the private sector to assess, display and benchmark the environmental performance of products, services and companies (Buttol et al. 2012) based on a comprehensive assessment of environmental impacts over the whole life cycle-the 'environmental footprint' (Product Environmental Footprint (PEF), Organization Environmental Footprint (OEF))
(2013/179/EU). Moreover, in the Communication on 'A European Consumer Agenda-Boosting confidence and growth' (COM 225 2012) it was emphasised that consumers could also have access to information about environmental impacts throughout the life cycle of the products they intend to buy and that they should be supported in easily identifying a truly sustainable choice. It was mentioned that the Commission will develop harmonised methodologies to assess the life cycle environmental performance of products and companies as a basis for providing reliable information to consumers. Such reliable and correct measurements and information on the environmental performance of investment projects form essential elements in the environmental decision-making process in companies. The EC is continuing work towards developing a uniform, European methodology for measuring the environmental performance of products and organisations. It contains a set of basic elements and rules in calculating the environmental characteristics of products and organisations throughout the life cycle (life cycle Assessment (LCA)). It should be also mentioned that environmental regulations were also tightened in other regions of the world, e.g. in Unites States (US) (Pennington et al. 2003; Gonzalez-Mejia et al. 2012), Australia (Van Berkel et al. 2008), Canada (Ryberg et al. 2014), China (Dai et al. 2012) and others. While the use of LCA in the development and application of policy is more common in EU (Jeswani and Azapagic 2015), the US has started to look towards the possibilities of life cycle information for policy decisions at both the federal and state levels (Bare 2011). Currently, the use of LCA in American Federal policy is limited to two agencies-Environmental Protection Agency (EPA) and Department of Energy (DOE) and exists more for technology assessment than for policy formulation (Reed 2012). LCA was introduced and integrated into the Federal Government Environmentally Preferable Purchasing Program, in the Energy Independence and Security Act (lcacenter.org). As decision makers are increasingly required to take into account potential short-, medium- and longterm environmental impacts of projects (Yeheyis et al. 2013), they more often use the LCA results during the investment projects (Johnsen 2014).

\section{Life cycle assessment as a basis for an environmentally friendly pathway (algorithm)}

LCA, as one of the techniques of environmental management, is recognised and recommended (Kulczycka and Lelek 2014) as a tool for assessing environmental projects (Rivera and Sutherland 2015) in many areas of economic activity (Baumann et al. 2011). Development and 
harmonisation activities have led to the establishment of an international standard (ISO; Reza et al. 2014), and this has been complemented by a number of guidelines and textbooks. According to the ISO (BS EN ISO 14040, 2009), LCA is an innovative concept for estimating environmental impacts related to various kinds of product (or service). It is worth noting that the perspective that LCA provides on the environmental performance of products has made it a central concept for both environmental management in industry and environmental policy-making in government and public administration (Meyer and Upadhyayula 2014). LCA focuses on environmental risks, creating the possibility of identifying these, as well as establishing a hierarchy and thus seeking technological solutions designed to maintain the optimum quality of the environment (Yan et al. 2011). Moreover, LCA results are quantitatively based on scientifically valid models and presented in value, i.e. for impact (Bare 2010), or damage categories (Das 2002). However, for each impact category, the value is determined in another unit (climate change- $-\mathrm{kg}$ of $\mathrm{CO}_{2}$ equivalent; acidification- $-\mathrm{kg}$ of $\mathrm{SO}_{2}$; eutrophication- $-\mathrm{kg}$ of $\mathrm{PO}_{2}$; energy use-MJ), therefore, it is not possible to compare them directly. But the use of normalisation and weighting-the next steps in the LCA methodologyrenders it possible to express the value of the potential environmental impact in one score value called eco-points. Even in the scientific literature-as the LCA methodology is still under development-the making of a public comparison of different technologies using eco-points is not recommended. It is widely used for internal comparison and it was proposed in the paper as a tool for the assessment of different technological options for the same investment project.

\section{The possible use of LCA-LCCA models in the assessment of investment projects}

Many papers propose the LCA method, which enables the most comprehensive identification, documentation and quantification (Kulczycka 2009) of potential impacts on the environment (Baumann and Tillman 2004) and the evaluation and comparison of all significant environmental aspects (Kicherer et al. 2007) as a tool for assessing the environmental aspects of investment projects (García-Gusano et al. 2015). As the LCA does not include any analysis of costs (Bare 2014), which is a major criterion in decisionmaking, the total cost of processes and flows associated with a product or system (Kannan et al. 2004) is estimated using a tool for life cycle cost analysis (LCCA) (Zhang et al. 2008). LCCA is especially useful when project alternatives that fulfil the same performance requirements, but which differ with respect to initial costs and operating costs, have to be compared in order to select the one that maximises net savings (Fuller 2010). LCCA is widely used for capital investment projects (mainly in building and construction) and it is recommended that it be used in public procurement in some countries as an economic analysis tool for engineering options that allows you to quantify the differential costs of alternative investment options for a given project. LCCA can be used to study either new construction projects or to examine preservation strategies for existing assets. Like LCA models, LCCA models vary in scope and depth and account for different kinds of costs. For example, LCCA models may account only for internal costs (agency costs), such as construction costs and maintenance costs; they may also account for social costs, such as user costs which are incurred by motorists who are delayed or detoured by construction related traffic, or environmental costs including the costs of environmental damage (Durairaj et al. 2002) associated with construction events (Zhang et al. 2008). The objective of the combined LCCA and LCA processes is to make these available to the engineering and management community and thus facilitate optimal structures early in the planning phase. However, despite LCA-LCCA models being described in the literature, e.g. usage of aluminium in innovative and impressive architectural solutions (Radlbeck et al. 2004), the estimation of the non-renewable energy use (and costs) and global warming potential in electricity generation from a typical oil-fired steam turbine plant (Kannan et al. 2004), and the assessment of buildings (Kreiner and Passer 2012) and pavement systems (Yu et al. 2013), there is no uniform methodology for their estimation. Therefore, the aim of this paper was to develop algorithms to link the LCA and LCCA models to promote the integrated assessment of investment projects in all branches of industry, while meeting the legal requirements for the projects analysed. The combination of LCA and LCCA results enables the assessment of ongoing or planned investments (e.g. the modernisation of manufacturing processes and new environmentally friendly technologies) and should be used as a priority in making strategic decisions (Baumann et al. 2011).

Different methods and indicators can be used in the decision-making process for comparing technological options. LCA allows one to quantify the impact of each technological option as an intermediate point or endpoint $(\mathrm{Pt})$. Midpoints, i.e. the results of impact categories, are usually presented in different values i.e. $\mathrm{kg} \mathrm{CO}_{2} \mathrm{eq} /$ functional unit, whereas endpoints are expressed in endpoint values i.e. Pt. Some LCA methods, for example Impact $2002+$, use both, whereas others, e.g. CML-IA, use only midpoints. The results presented in endpoints (proposed for the integrated assessment of environmental effects) have a higher level of uncertainty than midpoints (impact 
categories), but they are generally regarded as reliable. In fact, they are based on real data about the processes, the detailed balance of materials and scientific methods for determining them. Endpoints determine the potential level of impact on the environment. Higher values indicate higher impact on the environment.

The environmental assessment of analyses of technological options can be presented as endpoints. New technological solutions can be compared with the so-called baseline case or with other technological solutions presented i.e. in a BREF document. It is possible to prioritise solutions primarily in terms of the impact on the environment over time of the variants considered and of selected groups of investment projects with the same functions. In addition, each variant can be evaluated in order to assess its potential impact on the environment and this can be displayed at different stages in the production, use or development of the final product/process. In addition, by carrying out the LCA assessment technique, it is possible to introduce a variant or product that can lead to environmental balance (Kuan et al. 2007).

However, in the case of investments using public funds, especially those funded by the Structural Funds, it is necessary to examine the impact of the project on net economic welfare (social effects, including environmental), which is measured according to the principles described in the Guide to the cost-benefit analysis of investment projects issued by the European Commission and updated in 2008. These are usually grant-aided projects assessed by the traditionally calculated financial criterion net present value (NPV) $<0$. According to State aid rules, support can also be assessed as a private investment for investments such as those for environmental protection purposes. For such projects, the environmental and economic effects which are the basis for determining the indicators are usually calculated using a comparative analysis in relation to the existing situation, i.e.:

- for investment projects, it is assumed that the company did not go ahead - the 'zero option' (failure to act), or discontinued intervention;

- for products-a comparative analysis is made of several alternative products (functional units that fulfil the same features) or of the purchase of a new device and this is compared with the environmental impact of the current product.

The results of the survey indicate that for any investment decision not required by law, the decision is made on the basis of an economic calculation. Where the investment is seen to be financially inefficient, identification of the environmental effect may be the basis for an entrepreneur to seek financial support from the structural funds and special purpose vehicles. Identification of the environmental effect can also minimise the risk of environmental investments and improve the overall image of the company (Kulczycka 2011).

An algorithm has been developed to produce an account of eco-effectiveness investments made by private investors which takes into account the possibility of using LCALCCA results plus the enterprises' motives for undertaking ecological activities. This account includes a separate assessment of actions that are inefficient in terms of financial viability, but which should be carried out, for example, due to regulatory requirements. In this paper, the algorithms for the assessment of project environm ental performance are proposed for the following three options:

1. implementing environmental investments with an environmental objective (e.g. which are required by law, industrial policy and environmental regulations with NPV $<0$ ) - an evaluation is proposed on the basis of cost-effectiveness. This allows us to make a choice of the option with the lowest cost per unit of environmental effect obtained-minimising the life cycle cost to achieve the environmental objective (LCA-LCCA indicator of the cost);

2. modernisation and innovation investments (e.g. introduction of new, often innovative eco-technology); this is aimed to reduce the cost of manufacture or to modify the proposed products - an evaluation can be made through using the cumulative LCA-LCCA indicator. On this basis, options may be selected that harmonise economic and environmental goals including the assessment of any relevant hierarchy.

3. new investments, often discretionary projects (in a wider strategic sense) - an evaluation is made using the cumulative LCA-LCCA indicator. However, in this case, the eco-efficiency assessment of the project should be carried out in relation to a designated benchmark.

In this work, it is proposed that an efficiency investments account should be carried out to identify the economic and ecological effect of the investment project (including the cost of the product life cycle). The identification of the ecological effect could be made using LCA, whereas the economic appraisal would be made using LCCA. They can be combined to calculate the economic and environmental value added through the technological solutions proposed, and can be helpful in decision-making, especially for the assessment of environmental investment projects. 


\section{Proposals for algorithms for the evaluation of environment friendly investment projects}

\section{Algorithm for the evaluation of investment projects designed to meet environmental requirements using the LCA-LCCA indicator}

Some environmental investment projects are carried out to fulfil environmental requirements regulated by law (BS EN ISO 14001) BS EN ISO 14031. If there are no effective financial solutions, investors seek to minimise costs and actually minimise life cycle costs to achieve established environmental objectives. In this case, the LCA-LCCA indicator of life cycle cost is proposed. This is based on the concept of a method based on dynamic unit costs which indicates the cost of obtaining an individual environmental effect. The costs are expressed in local currency (e.g. EUR euro, US dollars) per unit of environmental effect, calculated using endpoints (i.e. Pt).

In order to calculate the values of the algorithm the following are proposed:

1. An analysis of the legal and socio-economic conditions in which the project operates and the motivating factors behind the implementation of environmental projects (legal and economic analysis).

2. The identification and assessment of the significant environmental aspects-such a procedure can be carried out in accordance with the requirements of EMAS, i.e. the selection of appropriate criteria and their associated weights (i.e. 1-3 points, where 3 points are assigned in the case of a dimension requiring an administrative decision; 2 points are assigned for the application, registration and/or payment of fees where agreements have been concluded in civil law and 1 is assigned when there are no legal requirements. The aspect is considered significant if the sum of points from all categories for a given aspect is greater than or equal to 6 , or there are legal and other requirements estimated to be 2 or 3 ). Identification can also be through using the LCA methodology where the results indicate a potential for a large impact on the environment and for an impact of the various components of 'inputs' (energy, materials) and 'outputs' (emissions, waste).

3. The determination of the environmental objective and activities allowing for a gradual reduction of the negative impact on the environment, which is considered a tool for continuous improvement. The objective of the investments envisaged is to fulfil the legal requirements and also to take into account the possibility of the significant environmental aspects identified.
4. The identification of various technological options for achieving the environmental objective, with a preliminary assessment of the legal, financial, operational and other business requirements related to the environment.

5. The performance of a simplified LCA assessment of acceptable solutions, with a quantification of the potential impact on the environment.

6. The verification of the environmental objective based on the LCA results (corrective action).

7. The prioritising of the potential environmental effects of the options analysed based on the LCA results. The LCA findings allow one to evaluate the potential impact on all protected areas (air, soil, water, etc.) and to identify dependences (relationships) between materials and processes used and the impact on the environment. It is proposed that at this stage the ecological effect is established in relation to the 'zero option' (the investment is discontinued), as well as between the different variants. The proposed method could be Impact $2000+$, as this allows the results of comparisons to be presented in endpoints $(\mathrm{Pt})$ and the environmental effect to be designated as the difference between the amount of Pt 'zero option' and the options analysed. Such an approach produces an easy to interpret designated environmental effect (the lowest value $\mathrm{Pt}$ is the smallest impact on the environment). This type of method (using the LCA analysis technique) also allows one to analyse the results in 11 impact categories and on the basis of other indicators developed with the use of the data from the second phase of the LCA, i.e. the material and energy balance. However, in the LCA method the potential impact on the environment is assessed as the average impact per inhabitant of Europe without aspects relating to local conditions.

8. The evaluation of the LCCA of different options, their prioritisation, and the choice of those which, on the basis of the results, fulfil the approved financial constraints. The LCCA values calculated for the project will be considered as the sum of the discounted costs that occur throughout the life cycle less any income (e.g. sale of raw materials) that may occur in each period of analysis. However, the basic criterion for selection is the cost of investment, which should be as low as possible but should not exceed the financial capacity resulting from the entrepreneur, and the operational life cycle.

9. Select the option with the lowest cost for obtaining an environmental effect, i.e., maximising the effect of environmental solutions at minimal costs, the selection of projects carried out with the use of the 
LCA-LCCA cost indicator described by the relationship (Kulczycka 2011):

$E E_{t}=\frac{\sum_{n=0}^{n} \frac{\mathrm{LCCA}_{n}}{\left(1+i_{k}\right)^{n}}}{\sum_{n=0}^{n} \frac{P t_{0}-P t_{t}}{\left(1+i_{s}\right)^{n}}}$,

where $E E_{t}$ is the LCA-LCCA indicator taking into account the cost of product life cycle concept for the selected option $(1 \ldots t)$, LCCA the life cycle costs in a given year of the project, $P t_{t}$ is the value of Impact $2000+$ for each design option $(1 \ldots t) ; P t_{0}$ is the value of Impact $2000+$ for the zero option; $n$ is year; $i_{s}$ is the discount rate for the assessment of environmental effects, the environmental discount rate proposed is $0.05 \% ; k$ is the discount rate for the assessment of environmental effects, the proposed rate is $5-15 \%$ depending on the nature and risks of the investment.

10 Interpretation of the results of the LCA-LCCA study of proposed solutions to determine their degree of reliability and uncertainty.

11 Assessment of the risk associated with local conditions; verify the planned projects on the basis of the results of the environmental impact assessment (EIA), accumulated income including loss of energy, best available techniques (BAT), etc., to carry out a sensitivity analysis, the assessment of the environmental factors that affect decisions both dependent and independent of the investor (e.g. resulting from the structure of energy consumption in the country analysed).

12 Selection of the project to be implemented. The proposed indicator can be used by companies to assess the solutions analysed in the project, and by financing units (e.g. Structural funds) or organisations which finance planned investments (private and public). The proposed algorithm is presented in Fig. 1.

\section{Algorithm for the evaluation of modernisation and innovation projects using the LCA-LCCA indicator}

This algorithm proposed for the evaluation of investment projects carried out by an entrepreneur (replacement, modernisation and innovation projects) primarily projects promoting environmental technologies and eco-innovative solutions. The introduction of proposals for green investment are primarily motivated by financial considerations associated with reducing the costs of production, for instance by reducing environmental charges or penalties. The identification of significant environmental aspects (such as environmental review, implementation of ISO 14000, EMAS, the requirements of competitors, LCA, etc.) is based on the search for such solutions. In addition, preliminary analysis of the results of the LCA technique could help to identify the environmental objective. In those cases, where the objective could be achieved without the necessity of incurring capital expenditure, appropriate action should be taken to this end. However, if expenditure is required, it is necessary to evaluate the effectiveness of investments, including life cycle costs. If the level of investment required is acceptable from the point of view of the source of funding, then a development target is determined which links the economic and environmental objectives. For the development target, various alternative models of technology solutions are prepared and assessment is made of the eco-effectiveness of the proposed solutions. If there is a situation where current technology could still be used, the sale of offsets or lost profits must be taken into account for depreciation purposes, and the liquidation value of the lost potential revenue from the sale of the assets exchanged. The financial efficiency of the proposed project can then be calculated as a new independent venture. Because in most cases economic and environmental effects should be recognised as present day values, another option would be to conduct an incremental flow analysis (surplus) of new investment in relation to the status quo. Similar calculations can be made for the environmental effects of each of the options analysed using LCA methodology. The results allow the preparation of a prioritisation of the cumulative environmental effects in relation to the 'zero option' and for a comparison to be made between the different variants. A hierarchy of design options should be prepared on the basis of economic accounting using dynamic methods and traditional indicators of NPV, internal rate of return (IRR), modified internal rate of return (MIRR) or profitability index (PI), which, after taking into account life cycle costs, takes the form of LCNPV, LCIRR, LCMIRR or LCPI.

The algorithm for calculating the values of eco-efficiency of such projects should adopt the following procedure:

1. Analyse the context of the project and the incentives affecting the implementation of environmental projects, including any anticipated regulatory requirements.

2. Identify and assess the significant environmental aspects-such a procedure can be carried out in accordance with the requirements of EMAS, i.e., by selecting the appropriate criteria and their associated weights. Identification can also be carried out using the LCA methodology-these results indicate the potential locations (factors) where there is heavy 


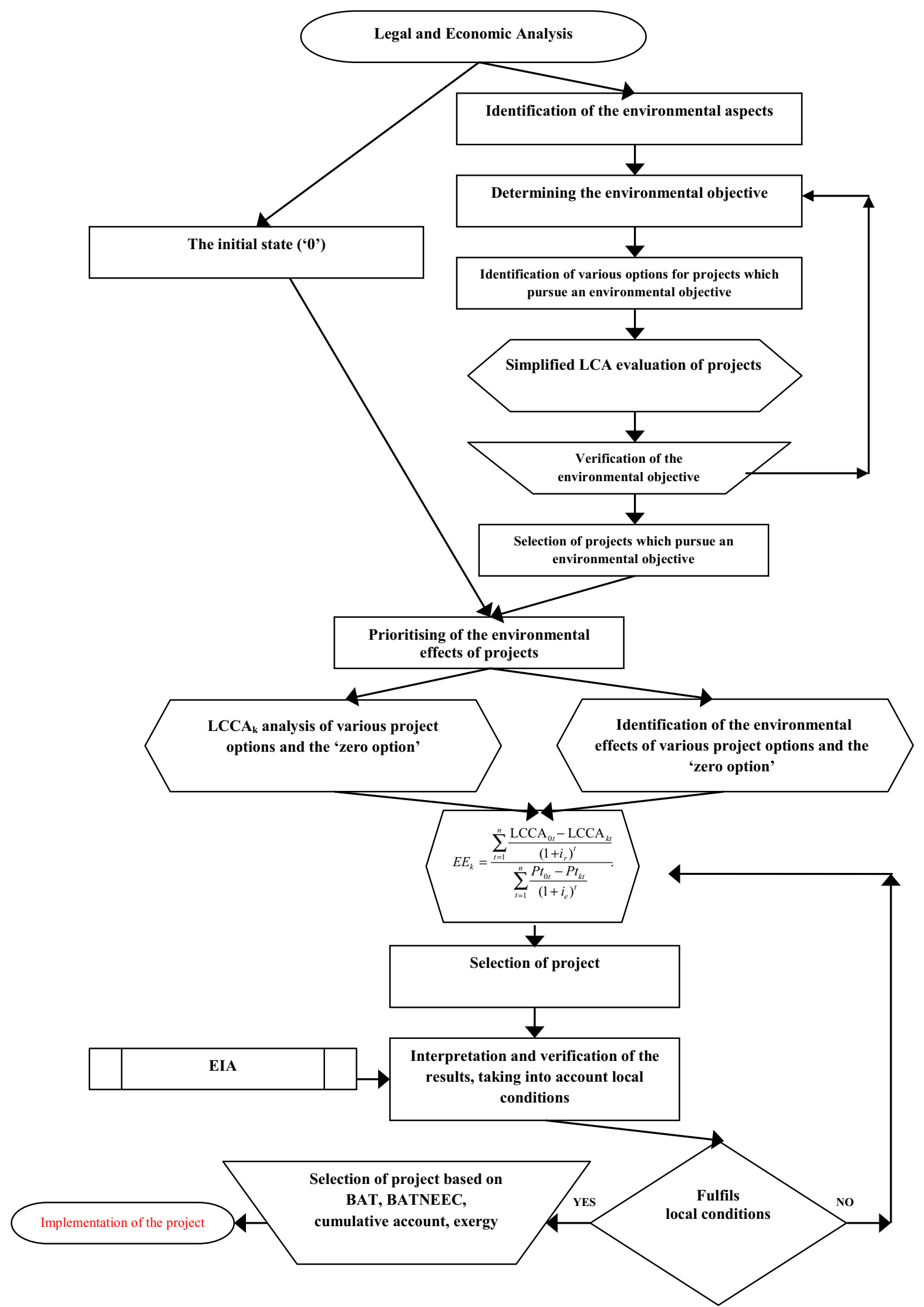

Fig. 1 Calculation algorithm for the LCA-LCCA indicator for an environmental investment project ( $L C A$ life cycle assessment, EIA environmental impact assessment, $L C C A$ life cycle cost analysis, $B A T$ best available techniques, BATNEEC best available techniques not entailing excessive costs) 
pressure on the environment and the impact of the various components of 'inputs' (energy, materials) and 'outputs' (emissions, waste).

3. Determine the environmental objective and those activities which permit the gradual reduction of the negative impact on the environment, which provide tools for continuous improvement.

4. Determine the potential opportunities for reducing the significant environmental aspects without investment and if they occur, follow the appropriate procedures e.g. in accordance with ISO 14001.

5. Determine the development goal which searches for eco-efficient alternatives.

6. Identify various options for technological projects, including an initial evaluation of the legal, financial (covering an acceptable level of financial resources to fund such investments) and operational requirements and other environmental issues within the contextual analysis.

7. Perform a simplified LCA assessment of acceptable solutions, with a quantification of the potential impact on the environment.

8. Verify the results of the development on the basis of LCA and the available financial resources.

9. Assess the economic viability of the options using the NPV method including life cycle costs (LCNPV).

10. Check whether the positive LCNPV projects are those that can accept other indicators including LCIRR, LCMIRR or LCPI. If so, and after verification of the financial situation and local conditions and the results of the EIA and LCA carry out the project.

11. For those projects with a LCNPV $<0$, check if it is possible to apply for funding from the Structural Funds, and if so, enter the applicable funds procedure.

12. For those projects with LCNPV $>0$, make a selection of the project. Perform an analysis, taking into account the concept of incremental investment and the economic efficiency assessment in relation to the 'zero option'. Then, prioritise the projects on the basis of the calculated LCIIRR value. Generally, it can be considered that if the LCIIRR value (\%) is higher, the project will be more cost-effective.

13. Prioritise the potential environmental effects of the projects analysed on the basis of the LCA results in relation to the 'zero option', i.e. the status quo. Compare the alternatives identifying the environmental effects by calculating the percentage (\%) increase in the value of Impact $2000+$ in relation to the 'zero option'. In the situation where there are environmental benefits during the implementation of a new project (in comparison with the existing situation), the value will be expressed as a percentage of a negative number determining the percentage reduction in environmental load in a given year. The LCA method only assesses the potential impact on the environment, which unlike EIA does not include differences arising from local conditions. However, the results of the LCA enable an integrated assessment of the life cycle, not just in the selected fields of protection such as air, soil, etc., which means that the assessment takes into account all of the environmental impacts. It is also possible that a much broader interpretation of the relationship between the materials and processes used and the impact on the environment can be made. Based on the LCA results, an environmental effect can be determined both in relation to the 'zero option', as well as between different projects with the same functional unit. Using the Impact 2000+ method, a comparison can be made in endpoints $(\mathrm{Pt})$, with the environmental effect designated as the percentage increase in the size of Pt between the 'zero option' and the options analysed. Such an approach is easy to interpret. The LCA analysis can also be undertaken using 11 categories of impact (e.g. climate change-the environmental effect will be determined as the percentage reduction of $\mathrm{CO}_{2} \mathrm{eq}$ ). Further indicators may also be collected during the second phase of the LCA study using data from the material and energy balances.

14. Determine the appropriate balance between the environmental and economic aspects. The current practice is a criterion of 0.7 for the products most commonly used for the economic scheme and of 0.3 for the environmental scheme. The range of the criterion is specified by a subjective structure and differs between various projects: 0.25/0.75 (economic/environmental criteria) (Bagchi 2004), 0.4/0.6 (Banar et al. 2007), 0.33/0.51 (Vego et al. 2008), 0.7/ 0.3 (Ersoy and Bulut 2009).

15. Select the projects with the highest ecological and economic effect on the calculated value of the cumulative LCA-LCCA indicator, described by the equation (Kulczycka 2011):

$$
E E_{n}=\mathrm{LCIRR}_{n} \times v_{\mathrm{e}}-\left(\frac{P t_{n}-P t_{0}}{P t_{0}}\right) \times 100 \times v_{\mathrm{ee}}
$$

where $E E_{n}$ is the cumulative LCA-LCCA indicator, taking into account the concept of the product life cycle for the selected project $(1 \ldots n), \mathrm{LCIRR}_{n}$ is the IRR for the ' $n$ th' option, including life cycle costs 
[\%], $v_{\mathrm{e}}$ is weight of economic criteria, $v_{\mathrm{ee}}$ is weight of ecological criteria, $P t$ is the value of Impact $2000+$ for individual projects $[P t]$, where $P t_{0}$ is the value for the status quo and $n$ is number of projects.

16. Check if the calculated rate is equal to or greater than the assumed discount rate. This assumption should result from the strategy adopted by the investor (who only implements those technologies for which the total increase in environmental and economic effects is higher than that resulting from the expected discount rate).

17. Interpret the results of the proposed solutions in order to identify the degree of reliability and uncertainty of the results, and to verify whether the proposed project will fulfil local conditions, e.g. due to the procedural requirements of EIA.

18. Verify the results by conducting additional analysis using methods such as accumulated income, including loss of energy, BAT, Best Available Techniques Not Entailing Excessive Costs (BATNEEC) etc.; perform a sensitivity analysis, the assessment of the environmental factors both dependent and independent of the investor (e.g. resulting from the structure of energy consumption in the country analysed) that may affect the project.

19. Select the project to implement.

The above algorithm enables the selection of projects according to a defined term namely eco- effectiveness as an investment. This includes the summary effects of economic growth and the increased environmental effect on the saving of resources and minimising of waste and emissions (Eco-balance) as compared to the existing situation or an appropriate alternative. The proposed algorithm is presented in Fig. 2.

\section{Algorithm for the evaluation of new investment projects using the LCA-LCCA indicator}

New investments are often associated with the implementation of environmental technologies, and often they are considered as particularly risky. These are called discretionary projects (in the broad strategic sense). They may be associated with the development of new projects (green field projects) or the use of existing sites or landfills (brown field projects). The eco-effectiveness assessment of such projects could be carried out on the basis of the cumulative rate of eco-effectiveness by referring the ecological effects to a fixed reference value. This can be determined on the basis of the average size of environmental impact of projects operating in Europe, or the average of national projects. It is important to determine the scale of the project (e.g. annual production) which should be comparable. If there are no data on the LCA results for projects with comparable size, an appropriate scale factor should be introduced. The selection of the reference value of the technology analysed should take into account:

- the proposed project should fulfil the BAT requirements for the industry (if there are any);

- the project should have the same or lower impact on environment, determined on the basis of the LCA methodology for the European industry concerned. This information is compiled by the European Commission (JRC-Ispra), as well as being available in existing commercial databases such as Ecoinvent;

- the project should have the same or lower impact on the environment as determined on the basis of the LCA methodology for the national industry (corresponds to the national average, where local conditions are important in the investment process).

It is proposed to apply the classical methods for the assessment of the use of life cycle costs, i.e. the discounted cash flow model and the calculated LCNPV, LCIRR, LCPI indicators, to assess the economic efficiency of these investments.

The proposed algorithm for such investments includes the following steps:

1. Carry out a context analysis of the conditions of operation of the project and the purpose of the project.

2. Identify the technical and economic conditions of all the necessary measures for the implementation of individual assignments that fulfil the assumed objective (project schedule).

3. Identify the various technological options for the impl ementation of the project with an initial evaluation of the legal, financial (including an acceptable level of fin ancial resources to fund such investments), operational and other requirements related to the business environment such as those arising from contextual analysis.

4. Perform initial financial analysis taking into account the life cycle costing and evaluation of the profitability of the investments for the selected option (LCNPV, LCPI, LCIRR) to evaluate the effectiveness of the project and to determine LCIRR and LCMIRR.

5. For an acceptable option in financial terms (LCNPV >0), carry out a simplified assessment of the project's impact on the environment with the use of LCA methodology, i.e. to quantify its impact on the environment.

6. Prioritise the potential environmental effects of the projects analysed on the basis of incremental LCA results in relation to the reference value. Compare alternatives-identify the environmental effect by calculating the percentage $(\%)$ increase in the value of the 


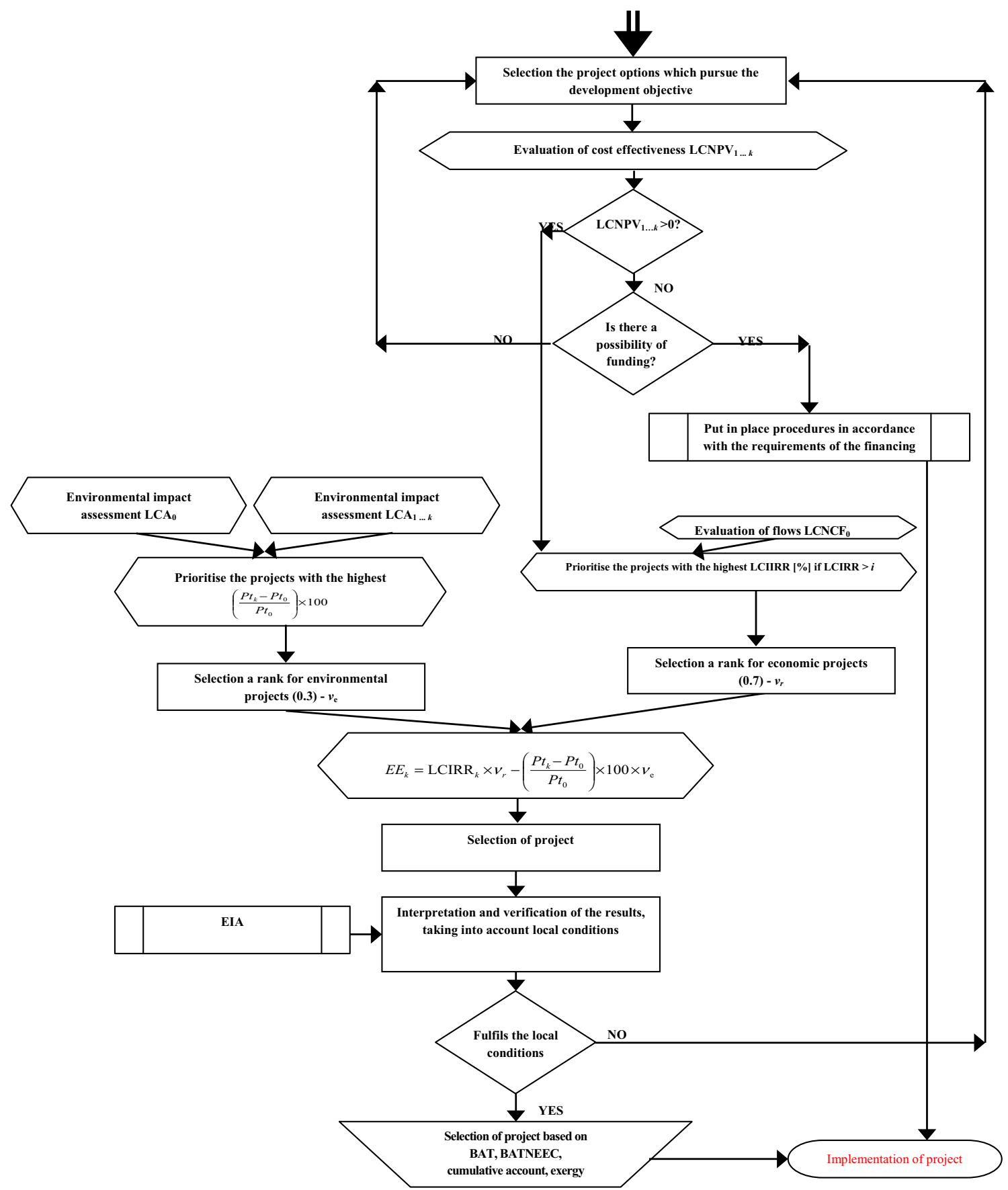

Fig. 2 Calculation algorithm for the LCA-LCCA indicator for modernisation investment projects ( $L C A$ life cycle assessment, EIA environmental impact assessment, $L C C A$ life cycle cost analysis, $B A T$ best available techniques, BATNEEC best available techniques not entailing excessive costs, $N P V$ net present value, IRR internal rate of return, $M I R R$ modified internal rate of return, $P I$ profitability index)
Impact $2000+(\mathrm{Pt})$ in relation to the reference value $\left(P t_{r}\right)$ taking into account the scale factor of the project (in the absence of data on similar size production). In the case of environmental benefits from the implementation of a new project compared to the existing situation, a percentage value will be a negative number which determines the percent reduction in environmental load.

7. Determine the appropriate status of the environmental and economic aspects. In current practice for products, 


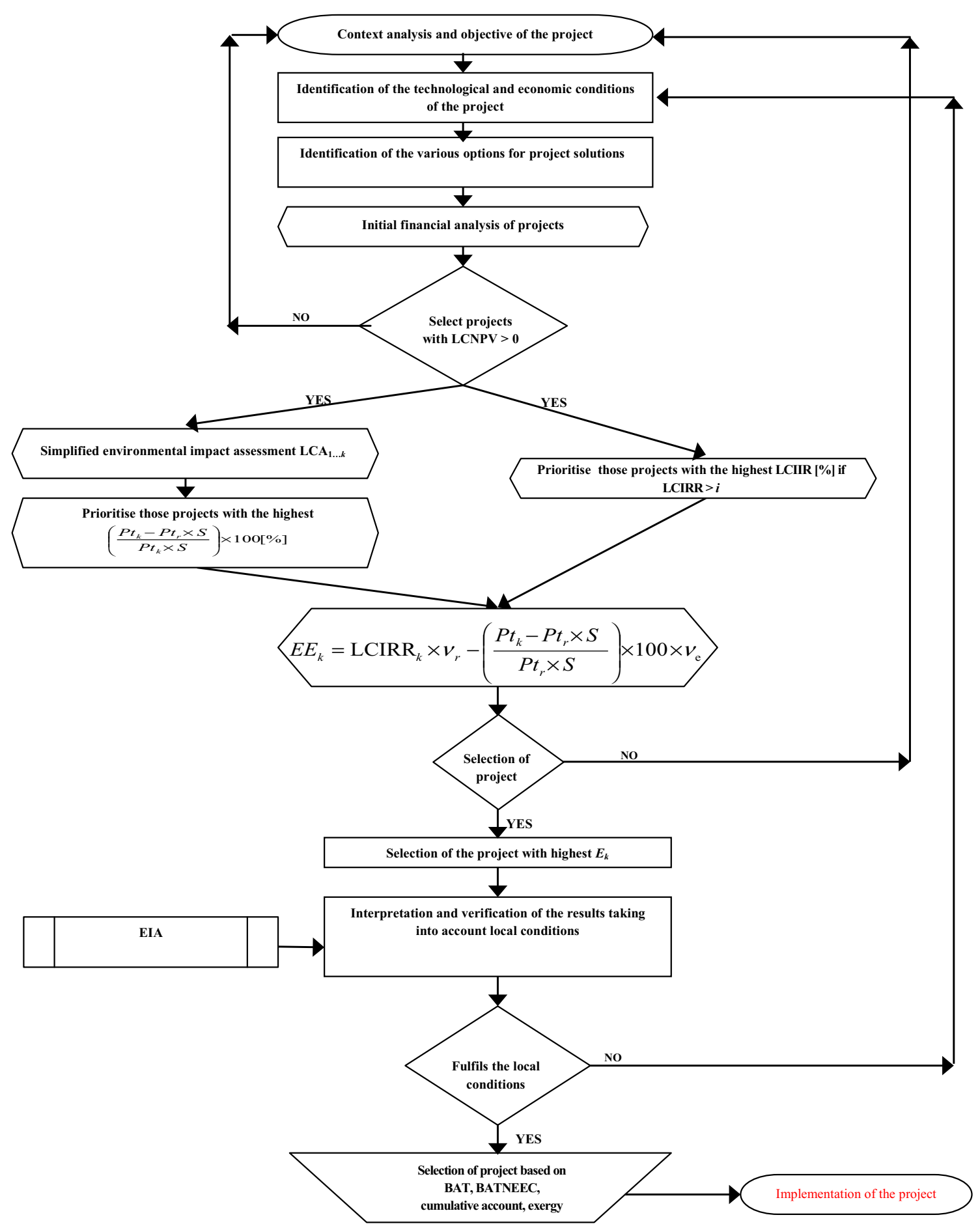

Fig. 3 Calculation algorithm for the LCA-LCCA indicator for new investment projects ( $L C A$ life cycle assessment, EIA environmental impact assessment, $L C C A$ life cycle cost analysis, BAT best available techniques, BATNEEC best available techniques not entailing excessive costs)

the most commonly used criterion is 0.7 for the economic criterion and 0.3 for the ecological criterion.

8. Select those projects with the highest environmental and economic effect on the calculated value of the cumulative rate of eco-effectiveness. It is described by the following equation (Kulczycka 2011):

$$
\begin{aligned}
E E_{n n}= & \mathrm{LCIRR}_{n} \times v_{\mathrm{e}}-\left(\frac{P t_{n}-P t_{r} \times S}{P t_{r} \times S}\right) \times 100 \\
& \times v_{\mathrm{ee}},
\end{aligned}
$$

where $E E_{n n}$ is the cumulative LCA-LCCA indicator taking into account the concept of the product life 
cycle for the selected project $(1 \ldots n) ; L C I R R$ is the IRR for option ' $n$ ', including life cycle costs [\%]; $v_{\mathrm{e}}$ is weight of economic criteria; $v_{\mathrm{ee}}$ is weight of ecological criteria; $P t$ is the value of Impact $2000+$ for individual projects $[P t]$, where $P t_{r}$ is the reference value of the investment; $s$ is the scale factor of the project; $n$ is number of projects.

9. Check if the value of the calculated ratio is equal to or greater than the assumed discount rate. This assumption should result from the strategy adopted by the investor, who will only implement technology for which the total increase in the environmental and economic effects is higher than the expected discount rate.

10. Interpret the results of the proposed solutions to determine the degree of credibility and uncertainty of the results, and verify that the proposed project fulfils local conditions, e.g. those arising from the procedural requirements of the EIA.

11. Verify the results by conducting additional analyses using methods such as accumulated income, including loss of energy, BAT, BATNEEC etc.; perform a sensitivity analysis, and an assessment of the environmental factors, both dependent and independent of the investor (e.g. resulting from the structure of energy consumption in the country analysed) that may affect the project.

12. Select the project to be implemented.

The above algorithm procedure allows one to select projects based on the eco-effectiveness of the new investment, which is defined as the sum of the economic effectiveness and environmental effectiveness specified by the investor of the project, assessed in comparison with a predetermined level (benchmarking), taking into account the scale of the process. The proposed algorithm procedure is presented in Fig. 3.

The proposed algorithms, in conjunction with the results of financial analysis conducted using the discount method, can be useful in decision-making on investments, when searching for optimal solutions from the standpoint of economic efficiency and environmental sustainability.

\section{Summary}

The introduction of the LCA-LCCA indicator to evaluate environmental effects can estimate, quantify and aggregate the potential impact of the object of the study on all components of the environment. It may be particularly important in the (eco) design of products where investment decisions are made concerning the implementation of new technological solutions, as well as in relation to modernisation processes. Calculated on the basis of a combination of the results of
LCA-LCCA studies of ecological effects and the profitability of the investment account enables the selection and prioritisation of planned investment projects. Their eco-effectiveness can then be evaluated, which frequently contributes to environmentally friendly solutions. LCA results can also be used to conduct structured and continuous action to prevent and reduce pollution and to improve the environmental management system (EMS) in accordance with the requirements of ISO 14001 which applies the PDCA approach-plan, do, check, act. It should complement the existing procedures for conducting environmental assessments and the implementation of an EMS. The algorithms proposed in this paper can be used in strategic planning in management systems, including EMS. Their role is to include the possibility of creating a management system and simplified search of investment solutions that are tailored to their physical and financial resources. In this perspective, strategic planning can be thought of as a process during which the decision-maker creates alternative scenarios to invest in various projects that provide new opportunities for growth. Introduction of the above proposed algorithms can identify and prioritise ecoeffectiveness solutions which will be subject to further evaluation and selection, and the choice of a portfolio of investment projects tailored to their physical and financial resources. Implementation of the proposed course of action supports investment decisions such as the classification of investment projects, the relative assessment of investments or decisions in which the goal can be achieved by implementing one of the many (often conflicting) projects, as well as the need to choose the most cost-effective option.

Acknowledgments The research work supporting this paper was performed in AGH University of Science and Technology in Cracow (Poland).

Open Access This article is distributed under the terms of the Creative Commons Attribution 4.0 International License (http://creative commons.org/licenses/by/4.0/), which permits unrestricted use, distribution, and reproduction in any medium, provided you give appropriate credit to the original author(s) and the source, provide a link to the Creative Commons license, and indicate if changes were made.

\section{References}

Akhtar S, Reza B, Hewage K, Shahriar A, Zargar A, Sadiq R (2014) Life cycle sustainability assessment (LCSA) for selection of sewer pipe materials. Clean Technol Environ Policy 17(4):973-992

Bagchi A (2004) Design of landfills and integrated solid waste management. John Wiley \& Sons, Hoboken

Banar M, Kose BM, Ozkan A, Acar IP (2007) Choosing a municipal landfill site by analytic network process. Environ Geol 52(4):747-751

Bare JC (2010) Life cycle impact assessment research developments and needs. Clean Technol Environ Policy 12(4):341-351

Bare J (2011) Recommendation for land use impact assessment: first steps into framework, theory, and implementation. Clean Technol Environ Policy 13(1):7-18 
Bare JC (2014) Development of impact assessment methodologies for environmental sustainability. Clean Technol Environ Policy 16(4):681-690

Baumann H, Tillman AM (2004) The Hitch Hiker's Guide to LCA. An orientation in life cycle assessment methodology and application. External organization, Lund

Baumann H, Berlin J, Brunklaus B, Lindkvist M, Löfgren B, Tillman AM (2011) The usefulness of an actor's perspective in LCA. In: Finkbeiner M (ed) Towards life cycle sustainability management. Springer, Dordrecht, pp 73-83

BS EN ISO 14001 (2005) Environmental management systemsrequirements with guidance for use. PKN Warsaw

BS EN ISO 14031 (2002) Environmental management-environmental performance evaluation-Guidelines. Warsaw

BS EN ISO 14040 (2009) Environmental management-life cycle assessment-principles and framework. Warsaw2009

Buttol P, Buonamici R, Naldesi L, Rinaldi C, Zamagni A, Masoni P (2012) Integrating services and tools in an ICT platform to support eco-innovation in SMEs. Clean Technol Environ Policy 14(2):211-221

COM 225 (2012) Communication from the Commission to the European Parliament, the Council, the European Economic and Social Committee and the Committee of the Regions, A European consumer agenda-Boosting confidence and growth. p 225

COM 571 (2011) Communication from the Commission to the European Parliament, the Council, the European Economic and Social Committee and the Committee of the Regions, Roadmap to a Resource Efficient Europe, p 571

Dai X, Li Z, Lin S, Xu W (2012) Assessment and zoning of ecoenvironmental sensitivity for a typical developing province in China. Stoch Env Res Risk Assess 26(8):1095-1107

Das TK (2002) Evaluating the life cycle environmental performance of chlorine disinfection and ultraviolet technologies. Clean Technol Environ Policy 4(1):32-43

De Benedetto L, Klemeš J (2010) The environmental bill of material and technology routing: an integrated LCA approach. Clean Technol Environ Policy 12(2):191-196

Durairaj SK, Ong SK, Nee AY, Tan RB (2002) Evaluation of life cycle cost analysis methodologies. Corp Environ Strategy 9(1):30-39

Elms RD, El-Halwagi MM (2010) The effect of greenhouse gas policy on the design and scheduling of biodiesel plants with multiple feedstocks. Clean Technol Environ Policy 12(5):547-560

Ersoy H, Bulut F (2009) Spatial and multi-criteria decision analysisbased methodology for landfill site selection in growing urban regions. Waste Manag Res 27(5):489-500

Fuller S (2010). Life-cycle cost analysis (LCCA). National Institute of Building Sciences, An Authoritative Source of Innovative Solutions for the Built Environment (www.WBDG.org, Washington)

García-Gusano D, Herrera I, Garraín D, Lechón Y, Cabal H (2015) Life cycle assessment of the Spanish cement industry: implementation of environmental-friendly solutions. Clean Technol Environ Policy 17(1):59-73

Gonzalez-Mejia AM, Eason T, Cabezas H, Suidan MT (2012) Computing and interpreting Fisher Information as a metric of sustainability: regime changes in the United States air quality. Clean Technol Environ Policy 14(5):775-788

Jasch C (2003) The use of environmental management accounting (EMA) for identifying environmental costs. J Clean Prod 11(6):667-676

Jeswani HK, Azapagic A (2015) Is e-reading environmentally more sustainable than conventional reading? Clean Technol Environ Policy 17(3):803-809
Johnsen FM (2014) Bridging Arctic environmental science and life cycle assessment: a preliminary assessment of regional scaling factors. Clean Technol Environ Policy 16(8):1713-1724

Kannan R, Tso CP, Osman R, Ho HK (2004) LCA-LCCA of oil fired steam turbine power plant in Singapore. Energy Convers Manag 45(18):3093-3107

Kicherer A, Schaltegger S, Tschochohei H, Pozo BF (2007) Ecoefficiency. Combining life cycle assessment and life cycle costs via normalization. Int J Life Cycle Assess 12(7):537-543

Kravanja P, Könighofer K, Canella L, Jungmeier G, Friedl A (2012) Perspectives for the production of bioethanol from wood and straw in Austria: technical, economic, and ecological aspects. Clean Technol Environ Policy 14(3):411-425

Kreiner H, Passer A (2012) Interdependency of LCCA and LCA in the assessment of buildings. In: Life-cycle and sustainability of civil infrastructure systems: proceedings of the third international symposium on life-cycle civil engineering (IALCCE'12), CRC Press, Vienna, p 370

Kuan CK, Foo DCY, Tan RR, Kumaresan S, Aziz RA (2007) Streamlined life cycle assessment of residue utilization options in Tongkat Ali (Eurycoma longifolia) water extract manufacturing process. Clean Technol Environ Policy 9(3):225-234

Kulczycka J (2009) Life cycle thinking in Polish official documents and research. Int J Life Cycle Assess 14(5):375-378

Kulczycka J (2011) Eco-efficiency of investment projects using the concept of product life cycle (Ekoefektywność projektów inwestycyjnych z wykorzystaniem koncepcji cyklu życia produktu). IGSMiE Academy of Sciences. Monographs 169. Cracow (in Polish)

Kulczycka J, Lelek $Ł$ (2014) Tools for promoting environmental sustainability in poland. In: Salomone R, Saija G (eds) Pathways to environmental sustainability. Springer International Publishing, Cham, pp 193-203

Lewandowska A, Kurczewski P, Kulczycka J, Joachimiak K, Matuszak-Flejszman A, Baumann H, Ciroth A (2013) LCA as an element in environmental management systems - comparison of conditions in selected organisations in Poland, Sweden and Germany. Int J Life Cycle Assess 18(2):472-480

Meyer DE, Upadhyayula VK (2014) The use of life cycle tools to support decision making for sustainable nanotechnologies. Clean Technol Environ Policy 16(4):757-772

Michelsen O, Fet AM (2010) Using eco-efficiency in sustainable supply chain management; a case study of furniture production. Clean Technol Environ Policy 12(5):561-570

Monteiro JGMS, Araújo ODQF, de Medeiros JL (2009a) Sustainability metrics for eco-technologies assessment, part I: preliminary screening. Clean Technol Environ Policy 11(2):209-214

Monteiro JGMS, Araújo ODQF, De Medeiros JL (2009b) Sustainability metrics for eco-technologies assessment, Part II. Life cycle analysis. Clean Technol Environ Policy 11(4):459-472

OEF (2013) Commission Recommendation of 9 April 2013 on the use of common methods to measure and communicate the life cycle environmental performance of products and organisations

Pennington DW, Bare J, Knodel R, Carroll G, Martin T (2003) Evaluating pollution prevention progress (P2P). Clean Technol Environ Policy 5(2):70-86

Radlbeck C, Dienes E, Kosteas D (2004) Sustainability of aluminium in buildings. Struct Eng Int 14(3):221-224

Reed DL (2012) Life-cycle assessment in government policy in the United States. Doctoral Dissertations, Knoxville

Reza B, Sadiq R, Hewage K (2014) Emergy-based life cycle assessment (Em-LCA) for sustainability appraisal of infrastructure systems: a case study on paved roads. Clean Technol Environ Policy 16(2):251-266 
Rivera JL, Sutherland JW (2015) A design of experiments (DOE) approach to data uncertainty in LCA: application to nanotechnology evaluation. Clean Technol Environ Policy 17(6): $1585-1595$

Ryberg M, Vieira MD, Zgola M, Bare J, Rosenbaum RK (2014) Updated US and Canadian normalization factors for TRACI 2.1. Clean Technol Environ Policy 16(2):329-339

Tsireme AI, Nikolaou EI, Georgantzis N, Tsagarakis KP (2012) The influence of environmental policy on the decisions of managers to adopt G-SCM practices. Clean Technol Environ Policy 14(5):953-964

Van Berkel R, Power G, Cooling D (2008) Quantitative methodology for strategic assessment of the sustainability of bauxite residue management. Clean Technol Environ Policy 10(4):359-370

Vego G, Kučar-Dragičević S, Koprivanac N (2008) Application of multi-criteria decision-making on strategic municipal solid waste management in Dalmatia, Croatia. Waste Manag 28(11): $2192-2201$
Yan MJ, Humphreys J, Holden NM (2011) An evaluation of life cycle assessment of European milk production. J Environ Manag 92(3):372-379

Yeheyis M, Hewage K, Alam MS, Eskicioglu C, Sadiq R (2013) An overview of construction and demolition waste management in Canada: a lifecycle analysis approach to sustainability. Clean Technol Environ Policy 15(1):81-91

$\mathrm{Yu}$ B, Lu Q, Xu J (2013) An improved pavement maintenance optimization methodology: integrating LCA and LCCA. Trans Res Part A 55:1-11

Zhang H, Keoleian GA, Lepech MD (2008) An integrated life cycle assessment and life cycle analysis model for pavement overlay systems. In: 1st International symposium on life-cycle civil engineering, Varenna, 907-915 June 2008

Zhu Z, Wang K, Zhang B (2014) Applying a network data envelopment analysis model to quantify the eco-efficiency of products: a case study of pesticides. J Clean Prod 69:67-73 